\title{
The Expression of Third Person in Older and Contemporary Varieties of English
}

\author{
Judy B. Bernstein \\ William Paterson University of New Jersey \\ bernsteinj@wpunj.edu
}

Contemporary varieties of English display word-initial th- across grammatical forms: definite articles (the), demonstratives (that, this), pronouns (them, they), existential subjects (there), relative pronouns (that), possessive pronouns (their), and others. Are these instances of th- merely unrelated coincidences or do they suggest an underlying systematicity? I argue that these forms share syntactic properties and an initial third-person morpheme (th-) corresponding to D(P) (see Longobardi 2004). Although many of the relevant forms are associated with definiteness, no form is absolutely barred from appearing in non-definite contexts, and some (e.g. existential there) are typically associated with indefiniteness. Nevertheless, several authors have identified English $t h$ - as a definiteness morpheme (Déchaine and Wiltschko 2002, Leu 2005, Campbell 1996) or a morpheme involved in deixis (Klinge 2004), which would be associated with $\mathrm{D}(\mathrm{P})$. The question for this talk is, is there any diachronic evidence to support the claim about English th- as a marker of third person?

Preliminary examination of the relevant Old English (OE) patterns offers no obvious direct support for the claim and might in fact be consistent with an analysis of $\mathrm{OE} p$ - as a definiteness or deixis morpheme, or with one of OE $b$ - as simultaneously a marker of definiteness and of third person. Deeper examination, however, suggests that subsequent changes in the English nominal system made way for the shift of $p$ - (from a marker of definiteness or deixis) to a general marker of third person. Evidence of this shift may even be found in contemporary varieties of English.

Broadly speaking, $\mathrm{OE}$ third person pronouns and demonstratives pattern with their contemporary counterparts in the following ways: third person pronouns overwhelmingly display word-initial $h$ - and demonstratives word-initial $b$-. OE nominative and dative forms for third person pronouns are illustrated in (1) and for demonstratives in (2) and (3) The nonparadigmatic forms underlined in (2) are interesting, especially since m.sg. se is identified as an early definite article (OE se wulf 'the wolf', Lass 1994).

$\underline{\text { OE third person pronouns }}$

$\begin{array}{lll}\text { m.sg. } & \text { NOM } & \text { DAT } \\ \text { n.sg. } & \text { hē } & \text { him } \\ \text { f.sg. } & \text { hit } & \text { him } \\ \text { pl. } & \text { hēo } & \text { hierre } \\ & \text { hīe } & \text { him }\end{array}$

(2) $\underline{\text { OE demonstratives (non-proximal) }}$

$\begin{array}{lll}\text { m.sg. } & \text { NOM } & \text { DAT } \\ \text { n.sg. } & \underline{\text { se }} & \text { pæm/pām } \\ \text { f.sg. } & \text { pæt } & \text { pæm/pām } \\ \text { pl. } & \underline{\text { sēo }} & \text { pære } \\ \text { pā } & \text { pæm/pām }\end{array}$


$\underline{\text { OE demonstratives (proximal) }}$

$\begin{array}{lll} & \text { NOM } & \text { DAT } \\ \text { m.sg. } & \text { pēs } & \text { pi(s)sum } \\ \text { n.sg. } & \text { pis } & \text { pis } \\ \text { f.sg. } & \text { pēos } & \text { pisse } \\ \text { pl. } & \text { pās } & \text { pās }\end{array}$

One important and sweeping subsequent change was the general loss of gender in the nominal system, except for the residual gender of the third person singular pronouns in contemporary varieties ( $\mathrm{him}, \mathrm{her},[\mathrm{h}] \mathrm{it}$ ), where it is tempting to take $h$-itself to be the marker of gender. The loss of gender was complete in the demonstrative forms, which in contemporary varieties of English display only a number (sg., pl.) alternation (this, these; that, those). A second important subsequent change was the borrowing of a Scandinavian third person plural paradigm (displaying word-initial $b$-) in late OE or early ME (Lass 1994; compare plural forms in (1)), which gave rise to the contemporary third person plurals: they, their, them. These two historical changes disrupted a symmetry (of gender) and an asymmetry (of marker, $h$ - or $b$-) between the pronouns and the demonstratives resulting in: a) a net loss of gender, except for residual gender in third person singular forms; b) a net gain of $p$ - forms for the third person plural pronouns; and c) no loss/gain of $b$-forms for the demonstratives, except that non-paradigmatic se/sēo loses out to the more regular $b$ - forms. (Klinge 2004 suggests that contemporary the is actually a reduction of OE proximal neuter pis.) Loss of the $p$ - ('thou') second person singular forms ( $p \bar{u}, b \bar{i} n, p \bar{e}, p \overline{\mathrm{e}} / p \overline{\mathrm{e}} c)$ further cleared the way for generalization of $t h$ - as a third person morpheme, but the lost paradigm could have originally been associated with the other OE $p$ - forms as a deictic morpheme. Textual data will be presented and discussed in more detail during the talk.

I have proposed that historical processes of simplification (of the gender and pronominal systems) and borrowing (of Scandinavian $b$ - forms) helped clear the way for a gradual shift to th- as a generalized third person morpheme in contemporary varieties of English. If so, are there more recent examples of a shift to $t h$ - in contexts formerly reserved for $h-$ ? Consider the cases of bound variable anaphora in (4).
a. $\quad$ Everyone $_{\mathrm{i}}$ thinks they' ' $^{\text {'re right. }}$
b. Every person ${ }_{i}$ thinks they' $y_{i}^{\prime}$ re right.
c. $\quad$ Someone $_{\mathrm{i}}$ loves their $_{\mathrm{i}}(\mathrm{own})$ mother.

In these types of examples, prescriptive singular he/his has given way to plural they/their in informal English.

\section{References}

Campbell, Richard. 1996. "Specificity Operators in SpecDP," Studia Linguistica 50:161-188.

Déchaine, Rose-Marie and Martina Wiltschko. 2002. "Decomposing pronouns," Linguistic Inquiry 33: 409-442.

Klinge, Alex . 2004. "Stating the case for $b$-root and $h w$-root determiners," Paper presented at Copenhagen Symposium on Determination, Copenhagen Business School.

Lass, Roger. 1994. Old English: A historical linguistic companion. Cambridge, UK: Cambridge University Press.

Leu, Thomas. 2005. "A note on these Germanic Demonstratives," ms., NYU.

Longobardi, Giuseppe. 2004. "On the syntax of denoting," Paper presented at the Copenhagen Symposium on Determination, Copenhagen Business School. 